\title{
THE ABNORMAL DEVELOPMENT OF PLAICE EMBRYOS AND LARVAE IN MARINE AQUARIA
}

\author{
By J. E. Shelbourne \\ Fisheries Laboratory, Lowestoft
}

(Plate I and Text-figs. I-I5)

We know that a mature female plaice can liberate many thousands of eggs into the sea during the spring spawning season in the southern North Sea (Simpson, I95I). We also know that a very small percentage indeed of these eggs develops into fish of marketable size. At all stages in its life history a plaice is confronted with environmental hazards, which, if not overcome, may have fatal consequences.

The pelagic egg and subsequent larval phase of marine teleosts appear to be particularly vulnerable to adverse conditions in the sea. Rollefsen (I930, 1932) demonstrated the lethal effect of agitation on early cod eggs and discussed wave-action as a mortality factor. Battle (I944) elaborated this work for other teleost species. Tester (I942) observed a high mortality of herring eggs spawned inshore, on weeds, along the south-east coast of Vancouver Island, and thought this loss was due to respiratory difficulties resulting from low carbon dioxide or high oxygen content of the water, a theory not substantiated by the work of Kelley (1946). There must also be considerable losses of eggs and larvae due to the activity of predators. Spent herring caught in the Southern Bight in early spring are frequently found with stomachs full of plaice eggs.

Undoubtedly, estimates of early mortality in the sea are needed for a better understanding of the population dynamics of a particular fishery. At the same time, rearing experiments in the laboratory, to determine the effect of known environmental changes on the development and survival of pelagic eggs and larvae, should give some knowledge of the possible causes of natural death.

Salt-water fish are notoriously difficult to raise. Petersen (1894), after several abortive attempts to rear plaice from artificially fertilized eggs, was emboldened to say, '. . . at the pelagic stage, after the yolk has been absorbed, it (the plaice post larva) cannot be kept alive in aquaria; at this stage the larva must be caught in open water and this is not always easy'. Cunningham (I894), using circulating water at $12^{\circ} \mathrm{C}$ in his aquaria, also failed to rear whiting, flounder and plaice eggs to the post-larval stage. Dannevig (I897) succeeded in taking a small proportion of an artificially fertilized batch of plaice eggs through and beyond metamorphosis for the first recorded time. 
Since these early attempts, Norwegian workers have had more success with plaice, cod and herring, accounts of which have been given by Rollefsen (I940) and Dannevig \& Hansen (1952).

At Lowestoft, during our recent experiments on plaice reared under static sea-water conditions in temperature-controlled aquaria, we encountered the usual difficulties. However, by the close observation of living material under known laboratory conditions, it becomes possible, first of all, to recognize normal healthiness, and then, against this standard, to detect even slight symptoms of abnormality. Knowledge of these symptoms and their causes aids the development of efficient rearing techniques and the interpretation of experimental results.

Some abnormalities of fish larvae in marine aquaria are already known. Dannevig (1897) observed that larvae from newly hatched plaice eggs could readily be divided into two fractions: a minority of healthy, richly pigmented individuals found ranging for food at all levels in the aquarium, and a majority of abnormal specimens which, after early hyperactivity at the surface, soon lost their pigment, and during long quiescent periods were to be found suspended head downwards near the bottom of the jar. Gorham's early work on the gas-bubble disease of adult marine fish (I90I) has been followed by observations on the same complaint in larvae with swim-bladders, by Kotthaus (1939), Soleim (1940) and Henly (1952). Plaice larvae are not affected by this disease. Bückmann, Harder \& Hempel (1953) found that herring larvae in lighted glass-vessels often sustain deformations of the head by continual collision with the walls of the jars. Attacks by Vibrio anguillarum and Lentospora cerebralis (Dannevig \& Hansen, 1952), and by bacteria, can produce abnormality and death in marine aquaria.

Trout larvae in freshwater aquaria frequently suffer from a fluid inflammation of the yolk-sac, known generally as Hydrocoele embryonalis, or as 'Dotterblasenwassersucht' by German workers. Dieterich (1938) proved the offspring of young parents to be more susceptible to 'yolk-sac dropsy' than the issue of older fish, and that offspring of crosses of related species are similarly prone.

The present paper describes a further common, abnormal condition in plaice, and attempts to explain it in terms of what is already known of the structure and physiology of pelagic marine larvae.

\section{Collection of Material and Rearing Methods}

Plaice eggs were periodically collected by stramin net in the Southern Bight and off Flamborough, during the spawning season of 1953. Additional supplies of eggs were available from an artificial fertilization carried out in the Irish Sea area. After separation from the rest of the catch, plaice eggs at various stages of development were kept in $7 \mathrm{lb}$. jars at $6^{\circ} \mathrm{C}$ with frequent 
water changes. On arrival in the laboratory, the eggs were transferred to fresh sea water from the spawning area in glass vessels cooled to $6^{\circ} \mathrm{C} \pm 0.5^{\circ}$ in a large tank. I 50-200 eggs were pipetted into each vessel of $1500 \mathrm{ml}$. capacity. The eggs were gently aerated up to the start of hatching; the emergent larvae were then removed into identical vessels, in batches of fifty. Artemia salina nauplii were introduced as food into the aquaria 4 days after hatching.

The shortcomings of this technique are manifold. Temperature alone was adequately controlled. In such small volumes of static sea water there must be inevitable ionic variations with the excretion and accumulation of carbon dioxide and other metabolites. Plaice larvae are able to adapt themselves to these gradual changes, some individuals more completely than others. A gross water renewal invariably kills off the weaker brethren. Ionic changes are also brought about on the addition of living food to the jars, and by the use of air from which the carbon dioxide has been incompletely removed.

Light conditions were uncontrolled; noticeable changes in larval activity were caused by the use of inspection lamps, thus disturbing the natural diurnal cycle of activity as witnessed by their feeding habits (Shelbourne, I953).

Where a supply of continually renewed and chemically constant sea water is available, many of the obstacles to the successful rearing of marine teleost eggs and larvae are removed. However, it must be recorded that during the I954 plaice-spawning season, batches of artificially fertilized eggs were taken through to a normal early post-larval stage with no water change and no aeration, under constant temperature and light conditions. On the introduction of washed Artemia nauplii into the jars, the majority of the larvae started feeding. Successive additions of food called for frequent water changes; it was under these rapidly changing physico-chemical conditions that the larvae began to sicken.

\section{The Features of a Normal LaRva and the COURSE OF ITS YOLK LOSS}

Text-fig. I is a diagram of a normal newly hatched plaice larva $6.5 \mathrm{~mm}$ long. The fore-, mid- and hind-brains are clearly seen through the transparent cartilage of the cranium, whilst the heavily pigmented eyes and expanded auditory capsules are the most conspicuous of the associated sense organs. The nervous tissue of the brain narrows into the nerve cord posteriorly, which, together with the notochord, developing median blood vessels, and investing muscle myotomes, forms the larval axis or trunk.

The angular mandible is normally mobile soon after hatching, its articulation with the upper jaw producing a mouth gape sufficiently wide to accommodate the large, thin-walled diatoms and small zooplankton of northern waters. The future branchial apparatus is as yet incomplete; the gill clefts are 
open, but the gill bars lack branchial filaments. Even at this early stage, the simple gut tube is already coiling to the right, and is wedged between the ventral surface of the larval axis and the dorsal side of the underslung yolksac. Sphincters divide the alimentary canal into fore-, mid- and hind-gut, opening ventrally at the anus. The liver is a conspicuous gut appendage lying just behind the heart.

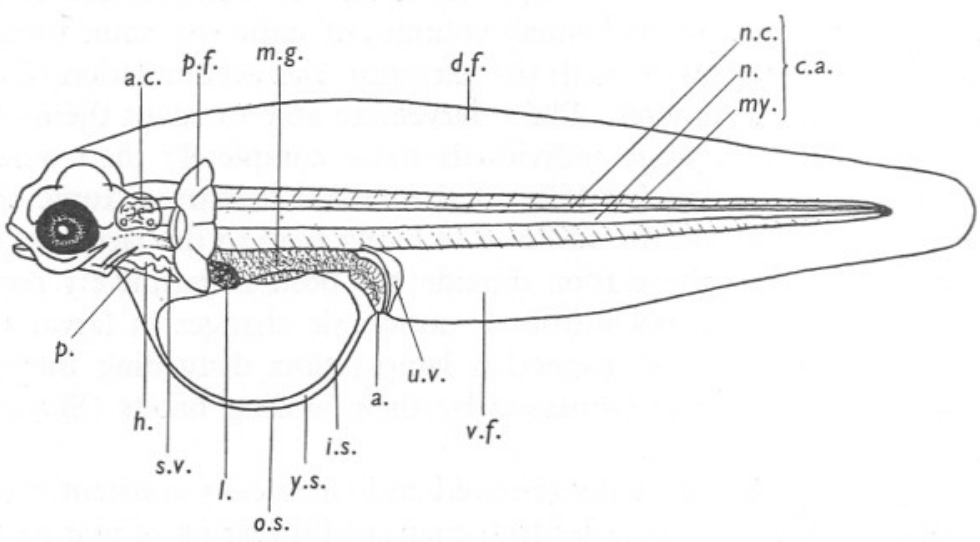

Text-fig. I. Early plaice larva: side view. a, anus; a.c., auditory capsule; d.f., dorsal marginal fin; h., heart; i.s., inner yolk-sac; l., liver; m.g., mid-gut; my., myotome; n., notochord; n.c., nerve cord; o.s., outer yolk-sac; p., pericardium; p.f., pectoral fin; s.v., sinus venosus; $u . v$. , urinary vesicle; $v . f$., ventral marginal fin; y.s., yolk-sac sinus.

In the ventro-lateral tissue of the trunk, above the gut, run the two urinary ducts, each of which connects in front with a pronephros behind the auditory capsules. The two ducts coalesce posteriorly as the urinary vesicle, opening behind the anus.

The heart, in its pericardium, lies underneath the oesophagus, and at hatching is differentiated into a muscular ventricle, an auricle, and a membranous sinus venosus. Anteriorly, the ventricle is twisted upwards and forwards to the ventral aorta, whilst posteriorly the sinus venosus opens directly into the yolk-sac sinus, a space between the membrane of the outer yolk-sac and the periblast layer, or inner sac surrounding the fluid yolk. There are neither cellular structures nor oil globules in the yolk, and it has no direct communication with the gut. The outer yolk-sac is but a ventral extension of the very thin integument completely clothing the larva, except at the gut and renal openings. This membrane forms the large marginal fin extending from the head above the larval axis, round the caudal extremity and back ventrally as far as the anal aperture. The two lamellae of the continuous fin are separated from one another, and supported by turgor in the serous subdermal space between (Text-fig. 4). The paired pectoral fins project outwards and backwards, just behind the auditory vesicles. 
A normal plaice is conspicuously pigmented at hatching, with yellow xanthophores and black melanophores, which have a stellate or corpuscular form, according to their degree of contraction. They are generally confined, in early larval life, to the superficial tissues of the main larval axis, though in good environmental conditions, xanthophores either develop on, or migrate into, the marginal fin above the caudal axis. Only black melanophores are found on the inner yolk-sac; these are sometimes also attached to the inner face of the outer sac, thus traversing the yolk-sac sinus.

Finer structural details are shown in Text-figs. 2-6, which are diagrammatic reconstructions of transverse sections through the yolk-sac and caudal regions of a normal newly hatched plaice larva.

The larval trunk (Text-fig. 4) consists of nerve cord, notochord, blood vessels and urinary ducts, all invested by the mesodermal musculature of the myotomes. During embryonic devlopment, a longitudinal fold has grown down each side from the axial mesoderm. The proximal edge of each fold, the splanchnopleure, contributes a lining of coelomic epithelium to the outer surface of the gut and its derivatives, by median fusion. The distal edges, or somatopleure, are reflected outwards to the integument, then inwards to join under the gut, and will eventually give rise to the ventro-lateral body wall of the post-larva, when the yolk has finally disappeared. At this early stage, the somatopleure is indifferently attached to the integument above the inner yolksac, whilst the ventral extension under the gut is thin and attenuated, and in some sections difficult to distinguish from the periblast tissue on the dorsal side of the inner yolk-sac. Its continuity ventrally is best seen in sections of the posterior gut region (Text-fig. 5).

The inner yolk-sac, or periblast of early workers, is a thick syncytial membrane (Meek, I9I3) surrounding the fluid yolk. It is formed by the activity of the ventral blastopore lip during gastrulation, and now lies inside the outer ectodermal yolk-sac, separated from it ventrally and laterally by a serous space, the yolk-sac sinus. This sinus is formed by the early breakdown into mesenchyme, of the extra-embryonal mesoderm layer laid down between the two sacs during gastrulation (Meek, I924). The integument of the outer yolk-sac is continuous with that of the marginal fin, and the yolk-sac sinus has lateral connexions with the lumen of the marginal fin due to the indifferent attachment of the somatopleure to the integument at gut level. The continuity of the yolk and fin spaces will be discussed in more detail later.

The transparent skin is very thin, and according to McIntosh \& Prince (I890) consists of an external layer of flattened, corneal cells and an inner Malpighian layer with a very loose cell texture. Meek (I924), on the other hand, states that in the cod the integument has a syncytial nature, reinforced by mesodermal elements. According to which view is adopted, the serous space between the integument and larval axis dorsally and the inner yolk-sac 


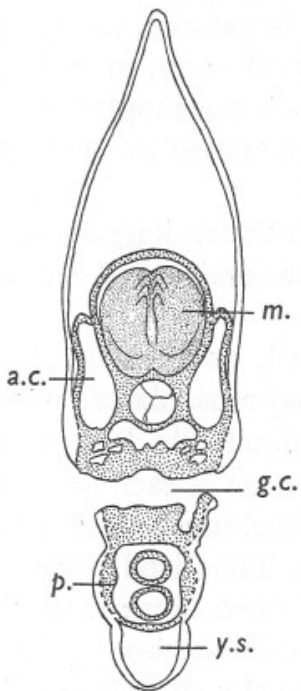

2

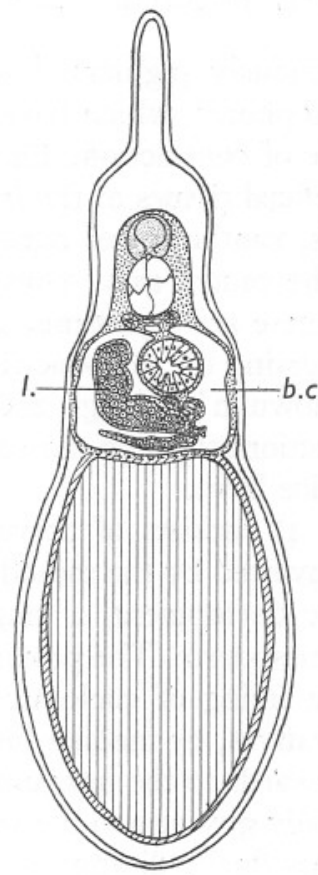

3

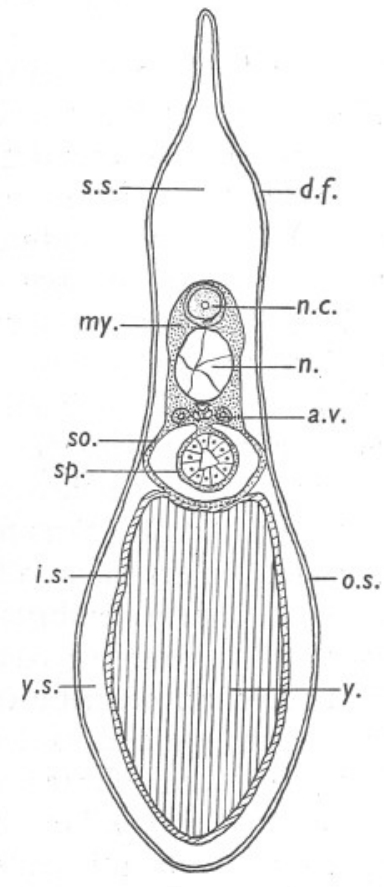

4
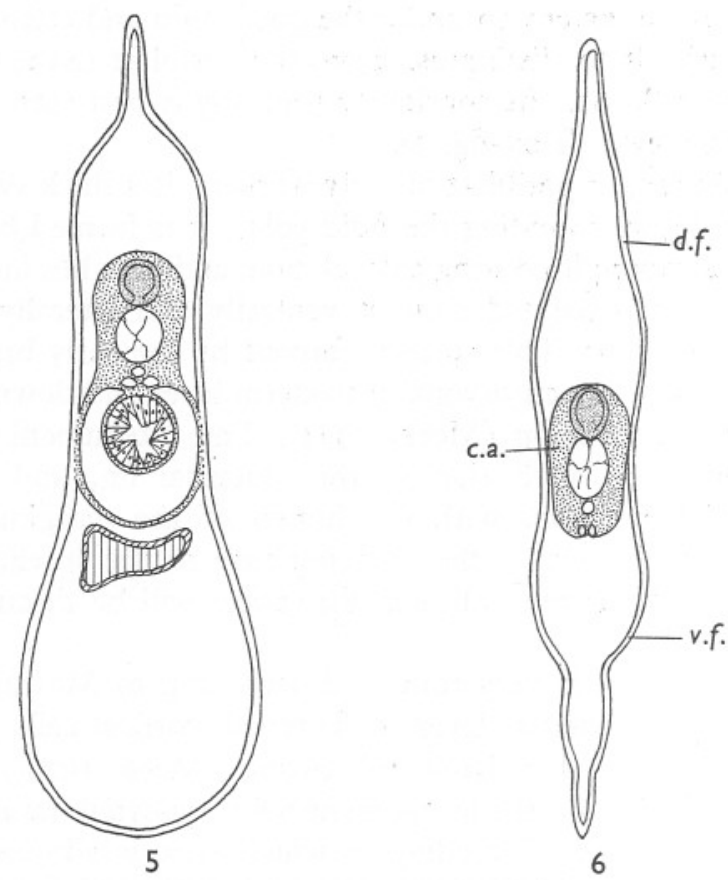

Text-figs. 2-6. Diagrams of transverse sections through an early plaice larva: through (2) pericardial region, (3) anterior part of yolk-sac, (4) mid-yolk-sac region, (5) posterior part of yolk-sac, and (6) caudal region. a.c., auditory capsule; a.v., axial vessels; b.c., body cavity; c.a., caudal axis; d.f., dorsal marginal fin; g.c., gill cleft; i.s., inner yolk-sac; $l$., liver; m., medulla; my., myotome; n., notochord; n.c., nerve cord; o.s., outer yolk-sac; p., pericardium; so., somatopleure; sp., splanchnopleure; s.s., subdermal space; v.f., ventral marginal fin; $y$., fluid yolk; y.s., yolk-sac sinus. 
ventrally is either a subepidermal or a subdermal space. The latter term will be used in this paper.

Text-fig. 3 is a transverse section through the liver. The lateral, longitudinal fusion of the somatopleure to the integument is still apparent, but just in front of the liver, where the somatopleure expands into the pectoral mesoderm, the attachment is considerably weakened (P1. I, fig. 2). Further forward still (Text-fig. 2), the segmented trunk mesoderm merges with the plate-like mesoderm and loose mesenchyme of the head, which is giving rise to skeletal structures, blood vessels and musculature. The head integument is closely integrated with the underlying tissue in front of the optic lobes of the brain; for the most part, the brain, eye and ear capsules lie in a fluid-filled space, continuous with that of the marginal fin. An embryonic downgrowth of two mesoderm folds under the head has produced the pericardium and heart by ventral fusion; at hatching, the wall of the pericardium is still largely separated from the skin beneath, to give the forward tip of the yolk-sac sinus.

In the caudal region (Text-fig. 6), behind the yolk, the close attachment of the integument to the sides of the somites of the larval axis divides the subdermal space into the lumina of the upper and lower portions of the marginal fin.

To sum up, a young normal plaice larva is clothed by a thin integument, which is strongly attached to the mesoderm in the anterior head region and to the sides of the caudal axis; it is indifferently attached above the yolk-sac sinus, particularly in the region of the pectoral fin. The inner yolk-sac is thus a bag of yolk lying in a ventral extension of this skin, its subdermal space (yolk-sac sinus) incompletely roofed over by somatopleural fusion with the integument. It is cut off behind by mes-ectodermal fusion round the rectum and urinary vesicle, and in front by the integration of the integument with the mesoderm on the underside of the head.

Although the normal embryo is coiled inside an egg-shell seldom greater than $2 \mathrm{~mm}$ in diameter, the freed larva may be $6 \mathrm{~mm}$ long, with straight axial structures and a turgid marginal fin. Shortly before hatching a marked diminution occurs in the volume of the yolk-sac system. The larva emerges with a boat-shaped yolk which continues to diminish smoothly and evenly for 8-Io days at $7^{\circ} \mathrm{C}$ (Text-figs. 7-9). Towards the end of larval life the small inner yolk-sac becomes pushed up into the arch formed by the looping intestine, so that the ventral surface of the animal, under the gut, is uninterrupted by pendulous projections of any kind. A small spherule of inner yolksac tissue may persist in what is now the posterior part of the body cavity for some time after the main mass of fluid yolk is lost. The final disappearance of this yolk vestige marks the end of the arbitrary larval stage and the beginning of the post-larval life of the plaice. 

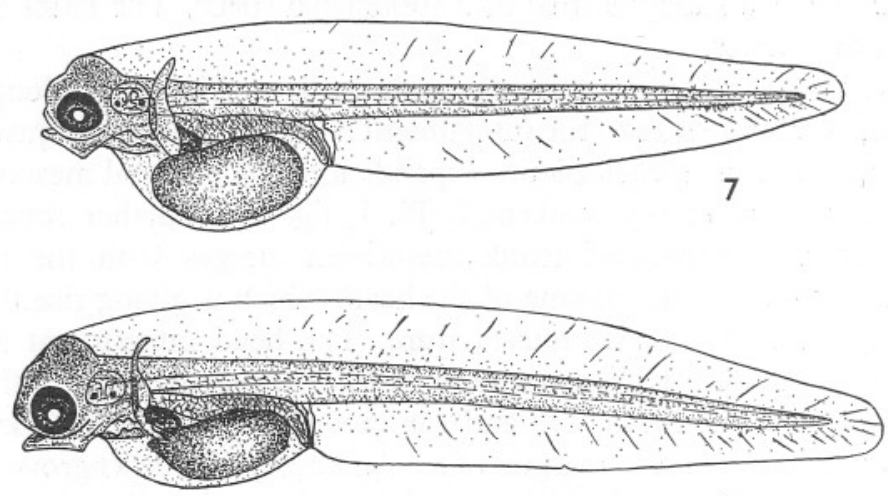

8

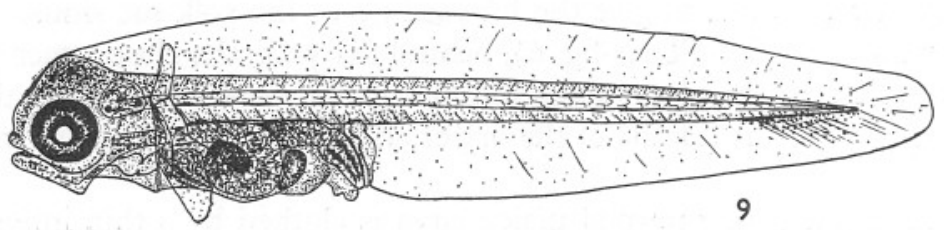

Text-figs. 7-9. Plaice larvae at (7) $24 \mathrm{~h},(8) 3-4$ days, and (9) 2-3 weeks, showing the normal course of yolk loss during development. Drawings are exact reproductions of preserved larvae. $\times \mathrm{I}_{3}$.

\section{AbNormal Yolk Loss AND the Development of Axial Bending}

In contrast to the normal course of observable yolk loss just described, tankreared larvae are prone to abnormal and uneven yolk resorption. Towards the end of the larval phase, affected plaice invariably develop a marked dorsoventral bending of the axial structures above the gut.

Abnormal individuals hatch with an unusually large inner yolk-sac, excavated anteriorly where the sinus venosus opens into the yolk-sac sinus (Text-fig. IO). This anterior dimpling of the yolk is very characteristic and is caused by an accumulation of plasma in the yolk-sac sinus underneath the pericardium. The larval axis may still show signs of embryonic curling as the fish lies at the surface, moving only when touched.

The subpericardial space enlarges as the inner yolk-sac decreases, so that the outer investing sac remains swollen. At the same time, the periblast tissue of the inner sac adheres closely to the inside surface of the outer sac, forming fingers of tissue extending forwards towards the heart (Text-fig. II). The dimpling of the yolk is usually intensified as the surface area of the outer sac slowly decreases. The yolk mass comes to occupy the posterior part of the outer sac, which, when viewed from above, appears much more bulbous than 

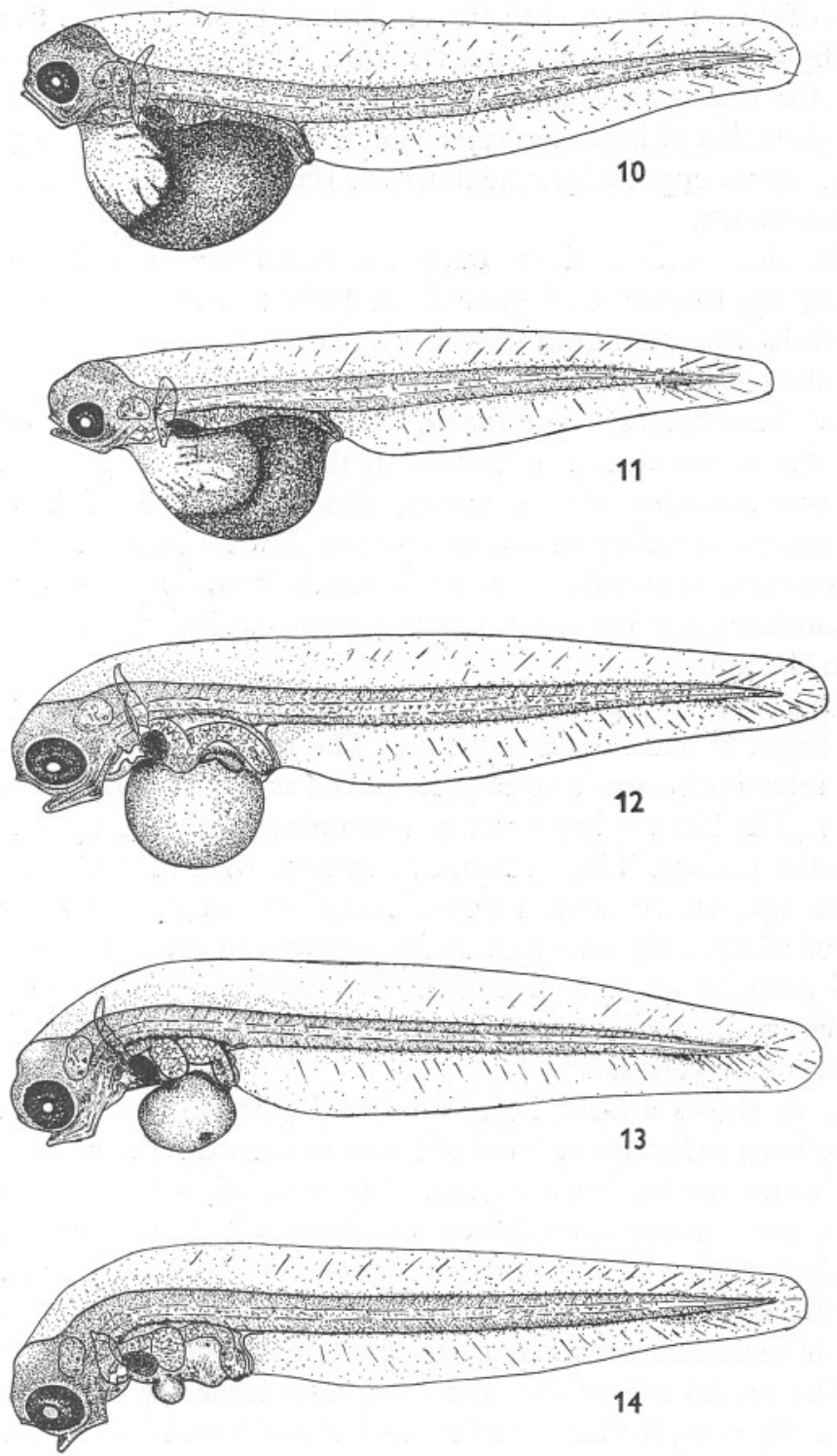

Text-figs. I0-I4. Plaice larvae showing abnormal course of yolk loss and the gradual bending of the axis above the gut during development: (IO) I2 h, (II) 24 h, (I2) 8 days, (I3) 2 weeks, and (I4) 3 weeks. Exact reproductions of preserved larvae. $\times \mathrm{I}_{3}$. 
the streamlined sac of a normal specimen. The larva is now active at or near the surface of the aquarium. In spite of abnormal yolk loss, the larva appears to be healthy and its axial structures straight. At a slightly later stage in yolk retraction, the cup-shaped anterior excavation becomes obliquely inclined, so that the direction of inner sac regression is now postero-dorsally, instead of posteriorly. At its upper edge, the inner sac remains in close contact with the visceral mass above.

Normally, that portion of the outer sac membrane underlying the heart progressively approaches and knits from before backwards with the pericardium, whilst the remaining yolk in its periblast retracts up into the arch formed by the coiling intestine. In abnormal specimens with a similar degree of yolk loss (Text-fig. I2) some fusion takes place under the heart, but it is limited by the accumulation of plasma in the original subpericardial space, which has now extended so as to occupy almost the whole of the outer yolksac. This space is in reality a swollen yolk-sac sinus. The anterior edge of the outer sac is characteristically reflected forwards from its point of attachment to the pericardium; the sac is now a turgid, subspherical, pendulous structure underneath the gut.

It is at this stage of abnormal yolk loss that the axial structures above the coiled gut begin to bend dorso-ventrally. The mouth starts to gape, and the arch of the intestine becomes more pronounced as the head and anus approach one another. The larva is hyperactive, swimming jerkily in a plane obliquely inclined to the surface. This behaviour contrasts with that of a normal larva of the same age, which cruises slowly round the depths of a jar with the minimum of effort, only interrupting its progress to investigate and perhaps catch food particles of a suitable size. During frequent quiescent periods, abnormal larvae lie upside down at the surface, supported by the swollen and buoyant outer yolk-sac.

Text-fig. I3 shows a larva in an advanced pathological state. The inner yolk-sac has been reduced to a band of tissue underneath the arching gut. The still turgid outer sac has been considerably reduced, whilst its subspherical proportions are further accentuated by increased fusion with the tissue beneath. The heart itself is noticeably congested in living specimens. Bending has intensified so as to incline the plane of the pectoral fin to the vertical, and the mouth is fixed in a permanent gape by tension on the mandibular musculature. The caudal axis is thin and compressed, the myotomes losing their distinctness. By now, the larva has lost its buoyancy and is to be found feebly spiralling near the bottom of the jar, showing no interest in offered food particles. In contrast to normal larvae, pigmentation is poor; some black chromatophores may persist, but all the yellow xanthophores have disappeared.

Finally, the outer yolk-sac becomes just visible as a slight ventral protuberance, and the head is bent downwards almost at right angles to the caudal axis (Text-fig. I4). The inner yolk-sac has disappeared, and the larva lies 
intermittently vibrating on the bottom of the jar. Dehydration soon follows, marked by the spread of opacity from the anterior and posterior extremities of the animal.

All abnormal larvae reared in artificial conditions do not display the same severe axial bending as the series just described. Generally speaking, the earlier the onset of abnormal symptoms, the greater is the distortion at the end of the larval phase, and the smaller are the chances of survival through to the post-larval stage.

Some idea of the high incidence of this complaint is given by experimental data for 1953. In January, $74 \%$ of North Sea plaice eggs used in the laboratory gave rise to severely bent larvae. In February, $66 \%$ were abnormal and only $5 \%$ of the remainder survived through to the post-larval stage. Bending also occurred in April on a smaller scale. Preserved specimens from earlier years frequently show signs of abnormality. Nor is this complaint confined to plaice-rearing work at Lowestoft. Fullarton (I89I) made a series of drawings of whole larvae, as part of his paper on the morphology of plaice development; the younger larvae show signs of abnormal yolk loss, whilst the oldest is very definitely bent.

\section{The Mechanics and Cause of Axial Bending}

The course of abnormal and normal yolk loss may now be reconsidered against the structural background. The first characteristic sign of abnormality is the accumulation of fluid in the anterior tip of the yolk-sac sinus, to form the 'subpericardial space', a structure erroneously considered normal by McIntosh \& Prince (I890) for the plaice, and by Ryder (I883) for the embryo shad. The space is significantly spherical in shape; it is contained partly by the outer yolk-sac and pericardial wall, and partly by the dimpled membrane of the inner yolk-sac, the tissue of which is left sticking to the inside surface of the outer sac during yolk loss. These indications suggest that the contents of the outer yolk-sac are under a slight pressure. Two conditions are necessary for the development and maintenance of this pressure: first, an increase in the tension of the outer-sac membrane, and secondly, the outer yolk-sac must be a closed system.

During the normal course of larval yolk loss, the surface areas of the inner and outer yolk-sacs rapidly diminish in phase with one another, until finally the inner sac completely disappears and the outer sac becomes the integument covering the thickening mesoderm under the gut. Abnormally, on the other hand, the speed of diminution of the outer sac is much less than that of the inner sac, due to the persisting accumulation of plasma in the sinus between the sacs. Although the outer sac membrane may have elastic properties, there is evidence that it loses surface area by an active process of degeneration and reorganization, rather than one of mechanical reassertion. 
Text-fig. I5 is a transverse section of a newly hatched larva, through the front part of the outer sac underneath the heart, showing this active process at work. Before degeneration sets in, the thin membrane is only sparsely sprinkled with nuclei. As degeneration proceeds, the affected area becomes much more richly supplied with vesicles and nucleated structures, some of which may be budded off externally, resembling the process of inner-sac corpusculation described by Ryder (1883) and Williamson (1898). Others open, and presumably discharge their contents at the outer face of the integument, leaving sharply defined depressions in the matrix of the membrane, which is thickened and puckered at this point. These activities can be followed in the living larva.

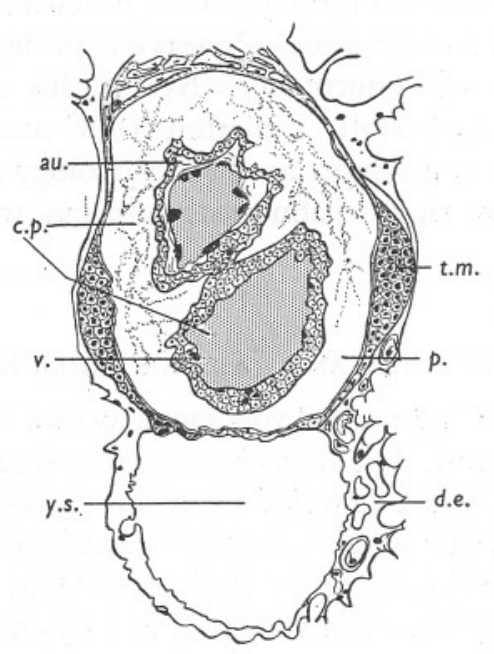

Text-fig. I5. Transverse section through the pericardium of a young plaice larva, $\times$ I50. au., auricle; c.p., coagulated plasma; d.e., degenerating ectoderm; p., pericardium; t.m., thickening mesoderm; v., ventricle; y.s., yolk-sac sinus.

Despite corpuscular discharge, the membrane remains imperforate. It is significant that integumental activity occurs for the most part anteriorly, and in close proximity to growing mesoderm. As a result, the two tissues knit closely together from before backwards, the surface area being reduced in the process. The early direction of mes-ectodermal fusion is shown by the receding anterior edge of the outer sac in Pl. I, figs. I-4; only at a late larval stage does similar activity start in front of the anus, nipping in the posterior edge of the sac. The somatopleural walls each side of the body cavity behind the heart become thickened, and, together with the ectodermal contribution from the degenerating outer yolk-sac, form the ventral body wall of the larva.

When yolk loss is normal, the tension set up in the outer sac, by its fusion with mesoderm under and behind the heart, pushes the remaining yolk in 
its periblast up into the arch of the intestine. Abnormal yolk loss does not prevent, but hinders, the trend towards degeneration of the outer sac membrane as it knits with the underlying mesoderm anteriorly; the tension thus generated fulfils the first condition needed to produce a slight pressure in this sac.

The second condition is that the outer sac remain a closed system. It was first shown by Fulton (I898) that a large volume of low density yolk diluent enters the egg at maturation in the ovary, thereby enabling it to float in sea water when liberated. It is clear that the overall volume enclosed by the embryonal integument can only decrease, during incubation, within the limit laid down by the initial reserve buoyancy, if the egg is to remain floating. As soluble nutrients are withdrawn from the dilute yolk during tissue-synthesis and respiration, so the yolk diluent accumulates beneath the integument and separates it from the underlying mesoderm to form the system of subdermal spaces so characteristic of pelagic embryos and larvae. In this way, the embryonal volume is maintained; but equally important is the fact that, as a result of integumental separation, the yolk-sac sinus is put in lateral communication with the lumen of the dorsal marginal fin, so that yolk derivatives have easy access to the growing tissues, without the intervention of the heart and ill-developed vascular system (Shelbourne, I955).

In abnormal plaice larvae the lateral subintegumental route connecting the yolk sinus with the fin space either fails to develop or becomes occluded. The somatopleure fold, by its non-separation from the integument at gut level and in the region of the pectoral fin, cuts off these two subdermal spaces. As the vascular circuit outside the yolk-sac sinus is simply a by-pass with neglible volume at this early larval stage, the outer sac is virtually a closed system, conforming to the second abnormal condition necessary for the maintenance of a slight internal pressure.

The inner yolk-sac is indistinctly separated from the body cavity by the weak ventral extension of the somatopleure under the gut. During abnormal yolk loss this thin membrane ruptures; the body cavity becomes continuous with the swollen sac underneath and is likewise inflated. The sac and body cavity system then has an hour-glass shape, the waist being an inpushing ring of fusing integument and mesoderm. As this ring closes under slight pressure, so the axial structures above the gut bend in conformity. Further mes-ectodermal fusion under the gut, to complete the ventral body wall, takes place with the axis thus bent, with the result that, when the pendulous sac disappears in anything up to a month, the distortion is maintained.

The cod also has a pelagic embryo, but it is not prone to the distortion already described for the plaice. Pl. I, fig. I, is a slightly oblique transverse section through the pectoral fin region of a young cod larva, to show the great extent of the subdermal space and the complete separation of the integument from the underlying structures. This separation is visible in the living larva towards the end of the yolk-sac stage. The yolk sinus is continuous with 
the lumen of the marginal fin, to give free access to yolk derivatives to all parts of the larva. The cod may be said to be a classical example of the pelagic mode of teleost egg development.

During normal plaice development such gross separation of integument from underlying tissue does not occur; turgor is never as great, and its degree is much more critical. In the static water conditions of our rearing experiments, it is likely that chemical deterioration of the water, with the accumulation of respiratory metabolites, particularly carbon dioxide (Burfield, I928), can impair the efficiency and impermeability of the embryonic and larval integument. Water will then be lost and salts gained, under the osmotic gradient, and with the reduction in turgor the integument will come to lie closer to the underlying mesoderm. If turgor is sufficiently reduced by poor conditions at an early embryonic stage, the important connexion between the yolk and fin spaces may never develop. Moreover, with loss of water there will be an increase in salt concentration. The internal salt balance must be restored, or the biochemical processes of normal development will be seriously affected. No mechanism of salt regulation for the marine fish embryo is yet known; if salt tolerance is slight, then it is easy to understand why marine larvae are difficult to rear in shore aquaria.

Significant metabolite accumulations are not likely to occur in the sea during the early life of the plaice, since chemical conditions are practically constant. One might therefore expect to find but a slight incidence of axial bending in larvae from plankton hauls. Only a single suspect has been found during the investigation of some thousands of sea larvae, although an adult plaice with a badly bent axis was landed on Lowestoft fish market in the spring of 1954 .

My thanks are due to Mr G. T. Thacker of this laboratory, for executing the drawings in this paper; and also to $\mathrm{Dr} \mathrm{H}$. A. Cole of the Fisheries Laboratory, Burnham-on-Crouch, and to Mr A. C. Simpson, of the Shellfish Experimental Station, Conway, for their helpful criticisms of the original manuscript.

\section{SUMMARY}

In 1953 laboratory attempts to rear plaice post-larvae were marred by the regular occurrence of structural distortion in late larval life. Normally the yolk-sac system diminishes rapidly and evenly during the short larval phase; abnormally the outer integument of the yolk-sac houses a persistent accumulation of plasma.

Under normal circumstances the yolk-sac sinus communicates laterally with the subdermal space of the dorsal marginal fin, providing free access of fluid yolk derivatives to the growing tissues. Abnormally the lateral channels become occluded or fail to develop, and yolk derivatives, under a slight 
pressure, are trapped in the outer sac. This prevents the smooth fusion of mesoderm and ectoderm to form the ventral part of the body wall, and ultimately causes structural distortion of the larval axis above the body cavity.

Cod larvae never suffer this distortion, because the turgor within their subdermal spaces is sufficient to separate completely the integument from the somitic mesoderm above the yolk sac. The degree of turgor in plaice embryos and larvae is much more critical, and water loss under the osmotic gradient, in poor tank conditions, may account for the described abnormality.

\section{REFERENCES}

Battle, H. I., I944. Effect of dropping on the subsequent hatching of teleostean ova. F. Fish. Res. Bd Can., Vol. 6, pp. 252-6.

BÜCKMANN, A., HARDER, W. \& HeMPel, G., I953. Unsere Beobachtungen am Hering (Clupea harengus L.). Kurze Mitt. fischereibiol. Abt. Max-Planck-Inst. für Meeresbiol. in Wilhelmshaven, Nr. 3, pp. 22-42.

Burfield, S. T., I928. The absorption of oxygen by plaice eggs. F. exp. Biol., Vol. 5, pp. $177-84$.

Cunningham, J. T., I894. Experiments on the rearing of fish larvae in the season of 1894. F. Mar. biol. Ass. U.K., Vol. 3, pp. 206-7.

DANNEviG, H., I897. On the rearing of the larval and post-larval stages of the plaice and other flat-fishes. Rep. Fish. Bd Scot., I5th Year (I896), pt. III, pp. I75-93.

Dannevig, A. \& HANSEN, S., I952. Faktorer av betydning for fiskeeggenes og fiskeyngelens oppvekst. Fiskeridir. Skr., Havundersøk., Bd. Io. No. I, 36 pp.

DieTERICH, E., I938. Die Hydrocoele embryonalis (Dotterblasenwassersucht) der Salmoniden. Z. Fisch., Bd. 36, H. 4, pp. 605-42.

Fullarton, S. H., I89I. On the development of the plaice (Pleuronectes platessa). Rep. Fish. Bd Scot., 9th Year (I890), pt. III, pp. 3II-I6.

FulToN, T. W., I898. On the growth and maturation of the ovarian eggs of teleostean fishes. Rep. Fish. Bd Scot., I6th Year (I897), pt. III, pp. 88-I24.

Gorham, F. P., I90r. The gas-bubble disease of fish and its cause. Bull. U.S. Fish Comm., Vol. 19, pp. 32-7.

HeNly, E., I952. The influence of the gas content of sea water on fish and fish larvae. Rapp. Cons. Explor. Mer, Vol. I3I, pp. 24-7.

Kelley, A. M., I946. Effect of abnormal $\mathrm{CO}_{2}$ tension on development of herring eggs. F. Fish. Res. Bd Can., Vol. 6, pp. 435-40.

Kotthaus, A., 1939. Zuchtversuche mit Heringslarven (Clupea harengus L.). Helgoland. wiss. Meeresunters., Bd. I, H. 3, pp. 349-58.

McIntosh, W. C. \& Prince, E. E., I890. On the development and life histories of the teleostean food-and other fishes. Trans. roy. Soc. Edinb., Vol. 35, pp. 665-944.

Meek, A., I913. The organisation of the teleostean egg. Rep. Dove Mar. Lab., I913, pp. 85-95.

Meek, A., I924. The development of the cod (Gadus callarias L.). Fish. Invest., Lond., Ser. 2, Vol. 7, No. I, 26 pp.

Petersen, C. G. J., I894. On the biology of our flat-fishes and on the decrease of our flat-fish fisheries. Rep. Danish Biol. Sta. Year I893, I46 pp. 
Rollefsen, G., 1930. Torske-egg med deformerte fostre. Aarsberetn. Norg. Fisk., I929, No. 2, pp. 85-95.

- 1932. The susceptibility of cod eggs to external influences. F. Cons. int. Explor. Mer, Vol. 7, pp. 367-73.

- 1940. Utklekning og oppdrettning av saltvannfisk. Naturea, nos. 6-7, pp. I97-2I7.

RYDER, J. A., I883. Observations on the absorption of the yelk, the food, the feeding and development of embryo fishes, comprising some investigations conducted at the Central Hatchery, Armory Building, Washington D.C., in I882. Bull. U.S. Fish. Comm., Vol. 2, pp. 179-205.

Shelbourne, J. E., I953. The feeding habits of plaice post-larvae in the Southern Bight. F. Mar. biol. Ass. U.K., Vol. 32, pp. I49-59.

- 1955. Significance of the subdermal space in pelagic fish embryos and larvae. Nature, Lond., Vol. I76, pp. 743-4.

Simpson, A. C., I95r. The fecundity of the plaice. Fish. Invest., Lond., Ser. 2, Vol. I7, No. 5, 27 pp.

Soleim, P., I940. Sildelarvene på vårsildfeltet. Fiskeridir. Skr. Havundersok., Bd. 6, No. 4, pp. 39-55.

Tester, A. L., I942. A high mortality of herring eggs. Prog. Rep. biol. Stas Nanaimo E Prince Rupert, no. 53, pp. 16-19.

Williamson, C., I898. Notes on some points in teleostean development. I6th Ann. Rep. Fish. Bd Scot. 16th Year (I897), pt. III, pp. 2II-I8.

\section{EXPLANATION OF PLATE I}

$\mapsto$, indicates progress of mes-ectodermal fusion, from before backwards.

Fig. I. Transverse section through the pectoral region of a cod larva; stained haematoxylin.

Fig. 2. Transverse section through the pectoral region of a plaice larva: stained haematoxylin.

Fig. 3. Preserved plaice larva; I day old. Early mes-ectodermal fusion anteriorly, under the pericardium.

Fig. 4. Three days old. Mes-ectodermal fusion now extends posteriorly beyond the pericardium.

Fig. 5. Four days old. Inner and outer yolk sacs much reduced. Integument knitted to underlying mesoderm beyond the level of the liver.

Fig. 6. Nine days old. Mes-ectodermal fusion almost complete ventrally.

Figs. I-2, $\times 68$.

Figs. 3-5, $\times 23$. 

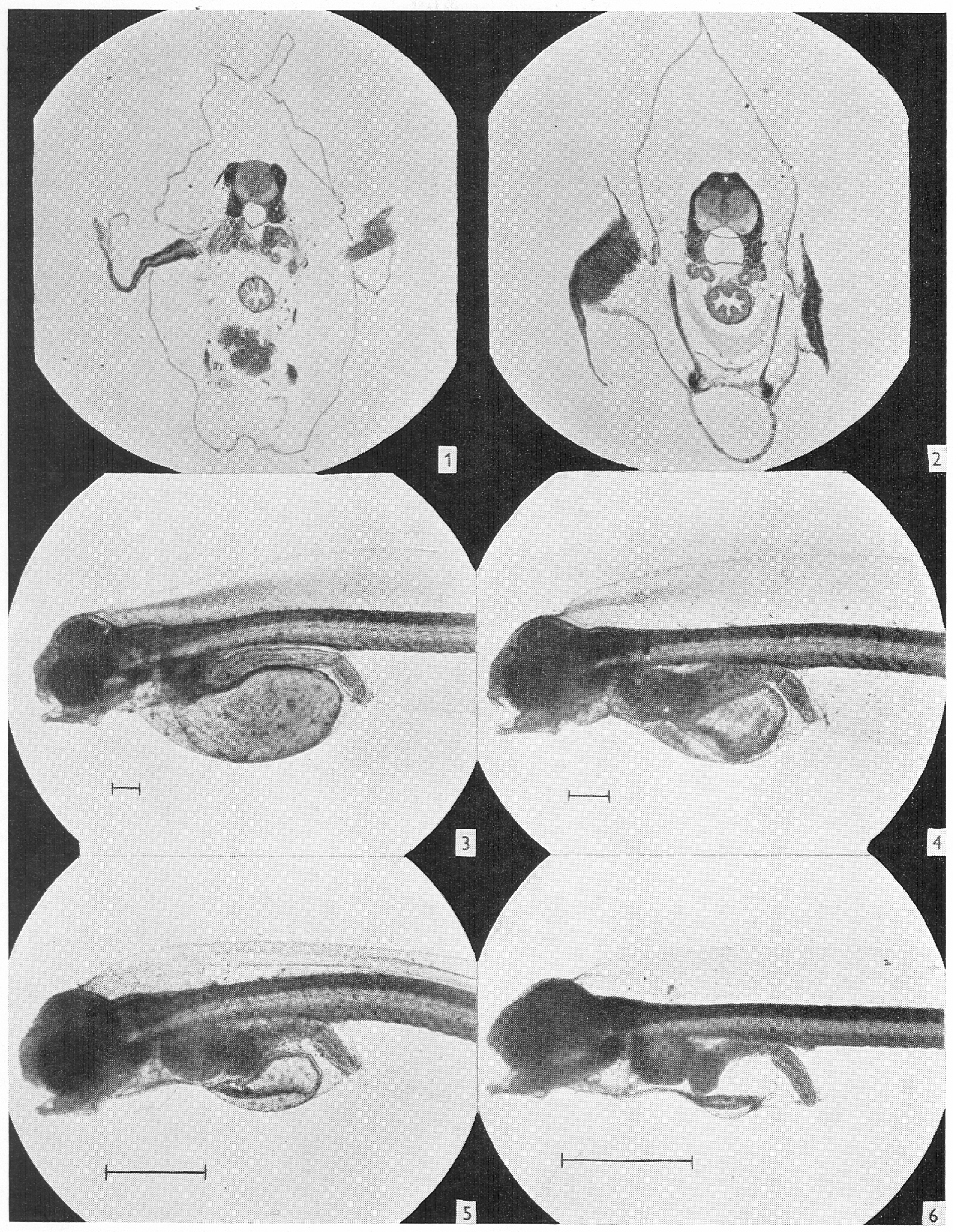

Figs. I-6.

(Facing p. I92) 